\title{
CAPÍTULO 05: GESTÃO INFORMATIZADA DE UM SETOR DE ASSISTÊNCIA ESTUDANTIL: UM ESTUDO DE CASO NO IFMG - CAMPUS BAMBUÍ
}

\author{
CAPÍTULO 05: GESTIÓN INFORMÁTICA DE UN SECTOR DE ASISTENCIA AL \\ ESTUDIANTE: UN ESTUDIO DE CASO EN IFMG - CAMPUS BAMBUÍ
}

\section{CHAPTER 05: COMPUTERIZED MANAGEMENT OF A STUDENT ASSISTANCE SECTOR: A CASE STUDY AT IFMG - CAMPUS BAMBUÍ}

\author{
Eduardo Cardoso Melo ${ }^{1}$; Gabriel da Silva ${ }^{2}$; Mateus Araújo Cruz ${ }^{3}$
}

DOI: https://doi.org/10.31692/978-65-88970-06-5.62-81

\section{RESUMO}

O emprego de recursos tecnológicos computacionais pode ser considerado como um dos principais meios propulsores para diversas transformações ocorridas na sociedade. Em se tratando de gestão organizacional, é quase impensável que empresas busquem atuação diversificada sem o apoio de ferramentas computacionais. Neste sentido, é consenso que a correta utilização de Sistemas de Informação tende a contribuir positivamente para o gerenciamento de processos de negócios. Este artigo objetiva apresentar como foi o processo de construção de um software cuja premissa inicial seria contribuir para a informatização de processos internos e com a gestão de um setor de Assistência Estudantil, no caso do IFMG - Campus Bambuí. Os aspectos teóricos relacionados com esta pesquisa estão baseados nos conceitos de Sistemas de Informação e inovação tecnológica na gestão pública. O gerenciamento das informações deste setor pesquisado era feito apenas com o uso de documentos de texto e planilhas eletrônicas, dificultando sobremaneira a integração de dados. A pesquisa foi desenvolvida entre o segundo semestre de 2018 até o final de 2019. As etapas para a produção do software tiveram como base a adaptação de propostas da metodologia ágil Scrum, com vistas a gerar e disponibilizar um produto final com funcionalidades aderentes às necessidades do público em questão. Após a implantação do software foi possível notar que os processos de tomada de decisão dos gestores passaram a contar com o importante auxílio de informações geradas pelo sistema. O compartilhamento de informações entre os servidores públicos também foi facilitado. Por fim, a informatização do processo de registro de frequência dos estudantes residentes na Moradia Estudantil do campus otimizou o trabalho dos servidores públicos do setor, especialmente no que se refere à manutenção dos dados que, até então, era feita exclusivamente em papel.

Palavras-Chave: Sistemas de Informação, Informatização de processos, Desenvolvimento Ágil, Institutos Federais, Auxílio na tomada de decisão.

\section{RESUMEN}

El uso de recursos tecnológicos computacionales puede considerarse como uno de los principales medios propulsores de varias transformaciones en la sociedad. En lo que respecta a la gestión organizacional, es casi impensable que las empresas busquen un desempeño diversificado sin el apoyo de herramientas computacionales. En este sentido, es un consenso que el uso correcto de los Sistemas de Información tiende a contribuir positivamente a la gestión de los procesos de negocio. Este artículo tiene como objetivo presentar cómo fue el proceso de construcción del software, cuya premisa inícial sería contribuir a la informatización de los procesos internos y a la gestión de un sector de Atención al Estudiante, en el caso de IFMG - Campus Bambuí. Los aspectos teóricos relacionados con esta investigación se basan en los conceptos de Sistemas de Información e innovación tecnológica en la gestión pública. La gestión de la información en este sector investigado se realizó únicamente con el uso de documentos de texto y hojas de cálculo, lo que dificulta enormemente la integración de datos. La investigación se llevó a cabo entre el segundo semestre de 2018 y finales de 2019. Los pasos para

${ }^{1}$ Professor Mestre, IFMG, eduardo.melo@ifmg.edu.br

2 Professor Mestre, IFMG, gabriel.silva@ifmg.edu.br

${ }^{3}$ Engenharia da Computação, IFMG, mateuscruz22@gmail.com 
la producción del software se basaron en la adecuación de propuestas de la metodología ágil Scrum, con el fin de generar y poner a disposición un producto final con funcionalidades que se adhieran a las necesidades del público en cuestión. Luego de la implementación del software, se pudo notar que los procesos de toma de decisiones de los gerentes comenzaron a depender de la importante ayuda de la información generada por el sistema. También se facilitó el intercambio de información entre servidores públicos. Por último, la informatización del proceso de registro de asistencia de los estudiantes residentes en la Vivienda de Estudiantes del campus optimizó el trabajo de los servidores públicos del sector, especialmente en lo que respecta al mantenimiento de datos que, hasta entonces, se realizaba exclusivamente en papel.

Palabras Clave: Sistemas de Información, Informatización de Procesos, Desarrollo Ágil, Institutos Federales, Asistencia en la Toma de Decisiones.

\section{ABSTRACT}

The use of computer technology resources can be considered as one of the main drivers for several transformations that have taken place in society. In organizational management context, it is almost unthinkable for companies to seek diversified performance without the support of computational tools. In this sense, it is a consensus that the correct use of Information Systems tends to contribute positively to the management of business processes. This article aims to present how the software construction process was, whose initial premise would be to contribute to the computerization of internal processes and to the management of a Student Assistance sector, in the case of IFMG Campus Bambuí. The theoretical aspects related to this research are based on the concepts of Information Systems and technological innovation in public management. The management of information in this sector was done only with the use of text documents and spreadsheets, making data integration extremely difficult. The research was conducted between the second half of 2018 and the end of 2019. The steps for the production of the software were based on the adaptation of proposals from the agile methodology called Scrum, with a view to generating and making available a final product with functionalities according to the needs of the target public. After the implantation of the software, it was possible to aid the decision-making processes of managers now have the important support information generated by the system. Information sharing between public employees was also facilitated. Finally, the computerization of the attendance registration process of students residing in the Student Housing on the campus optimized the work of the public servers, especially with regard to the maintenance of data that, until then, was done exclusively on paper.

Keywords: Information Systems, Computerization Processes, Agile Development, Federal Institutes, Aid in Decision Making.

\section{INTRODUÇÃO}

A Tecnologia da Informação (TI) tem participado diretamente das principais transformações ocorridas no mundo, em especial a partir do final do século XX, sendo facilitadora de diversas mudanças que impactaram os indivíduos tanto em aspectos profissionais quanto pessoais. Quando tais transformações envolvem o ambiente organizacional é possível destacar ainda mais o papel da TI, haja visto que por meio de seus recursos as empresas passam a ter condições de otimizar seus processos internos, incrementar a produtividade de seus colaboradores e obter resultados mais satisfatórios (VILELA et al., 2016; SILVA et al., 2016). As empresas modernas de variadas áreas de atuação dependem dos recursos da TI, como os Sistemas de Informação (SI), para a realização de seus negócios.

O nível de dependência das empresas para com sistemas informatizados é alto e em contínuo 
crescimento, especialmente se for considerada a evolução frequente dos recursos tecnológicos (MARCHIORI e MAINARDES, 2015. ROZA, 2017).

Quando é analisada a utilização de recursos de TI no gerenciamento de unidades educacionais no Brasil, em especial aquelas públicas, torna-se importante ressaltar que mesmo que avanços tenham sido notados recentemente, o contexto geral ainda indica um considerável conjunto de possíveis melhorias (FREITAS, CRESMASCO JÚNIOR e SOUZA, 2015). A ampliação do uso de recursos tecnológicos na administração pública precisa ser incentivada para que as pessoas, sejam elas os próprios servidores públicos ou qualquer indivíduo que necessite de um serviço, possam obter benefícios advindos do suporte prestado pela tecnologia (ARAÚJO, PINHEIRO JÚNIOR e ABREU, 2015; ASSIS, 2016; SZIMANSKI et al., 2015; ZORZAL, 2015).

Atualmente diversas ferramentas tecnológicas são utilizadas no ambiente organizacional do Campus Bambuí do Instituto Federal de Minas Gerais (IFMG), em especial softwares para auxiliar na gestão de seus setores e no acesso à informação por parte da comunidade acadêmica (CGTI, 2020). Ressalta-se, dentre essas ferramentas, a utilização frequente dos softwares denominados $\mathrm{GLPI}^{6}, \mathrm{SEI}^{7}$ e $\mathrm{Meu} \mathrm{IFMG}^{8}$. O primeiro oferece um sistema para controle automatizado de chamados internos do campus, em especial aqueles relacionados com manutenções diversas (laboratórios, infraestrutura, etc). O segundo é uma solução tecnológica para tramitação eletrônica de processos administrativos de toda a Instituição. O último software citado é, na verdade, o módulo de um Enterprise Resource Planning (ERP) contratado pelo IFMG junto à empresa Totvs para gerenciamento de informações acadêmicas, tais como frequência de alunos, notas e registros da Secretaria.

Em sua estrutura organizacional, o Campus Bambuí do IFMG dispõe de um setor específico para atendimento de demandas dos alunos, denominado Coordenadoria de Assistência Estudantil (CAE). Sua principal atuação consiste na oferta de diversificados serviços para a comunidade acadêmica, tais como alimentação no Restaurante Universitário, atendimentos especializados nas áreas de Odontologia, Medicina, Nutrição, Psicologia e Assistência Social, atividades de esporte e lazer e residência na Moradia Estudantil. Atualmente são disponibilizadas 250 vagas para que os alunos possam residir no campus, sendo 80 delas reservadas para estudantes do sexo feminino. Todos os residentes têm gratuidade em quatro refeições diárias e no serviço de lavanderia da Instituição (CAE, 2020).

\footnotetext{
${ }^{6}$ https://sistemas.bambui.ifmg.edu.br/glpi/

${ }^{7}$ http://sei.ifmg.edu.br/

${ }^{8}$ https://meu.ifmg.edu.br/
} 
Apesar de oferecer estes e outros serviços para uma comunidade de cerca de 2.500 alunos e estender o atendimento do Restaurante Universitário a aproximadamente 410 servidores e trabalhadores terceirizados, a CAE não contava, até o ano de 2019, com um software integrado capaz de auxiliar os servidores que lá atuam na condução e registro de suas atividades, bem como na automatização e otimização de rotinas internas. Toda a gestão documental do setor era feita em formulários de papel, documentos de texto e planilhas eletrônicas, praticamente impossibilitando qualquer demanda de integração de dados e, em especial, a produção de informações relevantes capazes de auxiliar os gestores nos processos de tomadas de decisão. Outra situação frequente era a falta de controle de acesso aos dados do setor, pois os documentos elaborados pelos servidores ficavam disponíveis em uma pasta compartilhada na rede interna sem qualquer análise de perfil sobre o usuário que a acessava. Agrega-se a este contexto um incêndio ocorrido no Data Center do campus que ocasionou a perda do equipamento onde os documentos da CAE eram salvos remotamente; quase todo o histórico de dados do setor foi perdido nesta ocasião. Por fim, a Moradia Estudantil possui uma série de rotinas internas que, até então, eram realizadas manualmente, como a chamada diária dos alunos residentes e o controle de saídas dos mesmos.

A proposta desta pesquisa foi compreender as reais necessidades gerenciais do setor de Assistência Estudantil do IFMG - Campus Bambuí para, com base neste entendimento, planejar, desenvolver e implantar um software integrado e personalizado que disponibilizasse funcionalidades capazes de auxiliar os servidores nas suas tarefas cotidianas, melhorando o atendimento ao público e possibilitando uma gestão íntegra e confiável das informações.

\section{FUNDAMENTAÇÃO TEÓRICA}

Esta seção visa apresentar os conceitos fundamentais diretamente relacionados com o tema abordado no presente trabalho, o qual envolve estudos sobre Sistemas de Informação e sua contribuição para a melhoria de processos administrativos na gestão pública.

\section{Sistemas de Informação}

Mattos (2017) descreve o conceito de Sistemas de Informação como sendo sistemas com especialização em processar e comunicar dados por meio de módulos interligados entre si em uma rede comum. De Sordi e Meireles (2018) também enfatizam o caráter abrangente dos Sistemas de Informação a partir do momento que eles envolvem e integram em sua utilização vários atores e componentes, porém nada disso seria possível sem o devido 
tratamento aos dados brutos que são inseridos nos sistemas. Na visão desses autores, os Sistemas de Informação tratam, prioritariamente, de dados que podem apresentar alguma importância para a organização quando processados e integrados, gerando informações que permitam uma tomada de decisão com maior embasamento.

Uma das definições mais aceitas sobre os Sistemas de Informação é apresentada por Laudon e Laudon (2015), ao afirmarem que eles podem ser visualizados como um conjunto de módulos que atuam relacionados (normalmente de forma direta) com o intuito principal de auxiliar o gerenciamento organizacional e os processos de tomada de decisão a partir do trabalho intenso com informações.

Batista (2017) apresenta uma válida classificação dos diversos tipos de sistemas que podem ser utilizados por organizações como auxílio à gestão. Neste contexto, os sistemas poderiam ser classificados com base na sua forma de utilização, no formato de retorno proporcionado para a tomada de decisão e, por fim, de acordo com a quantidade de pessoas relacionadas com ele. Quanto às nomenclaturas utilizadas para caracterizar os diversos tipos de sistemas, o autor divide-as em sistemas empresariais básicos, sistemas de automação de escritório, sistemas de informação gerencial, sistemas de suporte à decisão, sistemas de suporte executivo e sistemas especialistas.

Gomes Filho (2018) ressaltam o atual momento da tecnologia e sua ampla utilização nas mais variadas áreas da sociedade, indicando que o emprego de Sistemas de Informação é viável na maioria das situações que requerem melhorias organizacionais. Entretanto, é fundamental que sejam conduzidos estudos contínuos para averiguar se o Sistema de Informação se mantém alinhado com os objetivos da organização e de seus usuários ao longo do tempo de sua utilização.

\section{Tecnologias da Informação (TI) na Gestão Pública}

Uma das áreas de estudo que abordam a aplicação de inovadoras tecnologias informação no contexto da Gestão Pública é conhecida como "Governo Eletrônico government)". Seu foco é compreender como as novas ferramentas tecnológicas podem auxiliar os membros da administração pública na melhoria de vários aspectos da gestão, notadamente aquele que trata sobre o relacionamento do governo com os cidadãos, empresas e unidades de sua própria estrutura (DIAS, SANO e MEIRELES, 2019).

No entendimento de Rabelo et al. (2019), o governo eletrônico precisa ser analisado com uma visão ampla que permita compreende-lo como um novo modo do governo cumprir o papel do Estado na sociedade de maneira efetiva, ao invés de somente ser considerado como a 
aplicação de tecnologias para automatizar processos.

Brognoli e Ferenhof (2020) apresentam um amplo estudo sobre como vem sendo conduzida a transformação digital no governo brasileiro desde o ano 2000. Dentre diversos indicadores favoráveis à utilização de recursos tecnológicos na administração pública, os autores destacam a grande diferença entre o custo do atendimento presencial e do virtual, indicando a importância de o governo buscar constantemente a implementação de ações que gerem efetiva economia de recursos financeiros e de pessoal.

\section{METODOLOGIA}

Considerando a obra de Wazlawick (2014), este trabalho pode ser caracterizado de acordo com o estilo "Apresentação de um Produto", cujo foco está mais relacionado com o tipo de pesquisa exploratória e busca compartilhar informações sobre um produto recémdesenvolvido e disponibilizado para uso. Trata-se de um trabalho com abordagem predominantemente qualitativa e de natureza aplicada. De acordo com Freitas e Prodanov (2013, p. 70), “a pesquisa qualitativa não requer uso de métodos e técnicas estatísticas, sendo o ambiente natural a fonte direta para coleta de dados e o pesquisador o instrumento-chave". Silveira e Córdova (2009) caracterizam a pesquisa aplicada como sendo aquela cujo foco é a solução de problemas específicos, objetivando construir novos conhecimentos práticos a respeito do que é estudado. No que se refere aos procedimentos, esta pesquisa pode ser categorizada como experimental e estudo de caso. Para Wazlawick (2014, p. 43), na pesquisa experimental o pesquisador "provocará alterações no ambiente a ser pesquisado de forma a observar se cada intervenção produz os resultados esperados”. Já o estudo de caso é entendido por Gil (2019) como sendo o estudo abrangente de determinado objeto, fazendo com que seja possível conhecê-lo em detalhes.

Em relação ao gerenciamento do projeto de desenvolvimento do software, algumas propostas da metodologia ágil Scrum foram adaptadas e utilizadas, tais como a definição dos backlogs (produto, versões e sprints) e cerimônias para acompanhamento e discussões sobre o projeto. As atividades desta pesquisa foram realizadas, em sua maioria, no Laboratório de Sistemas Computacionais (LSC) do Grupo de Pesquisa em Sistemas Computacionais (GPSisCom) do IFMG - Campus Bambuí. Neste ambiente, os participantes tiveram acesso a todos os recursos necessários para o desenvolvimento das atividades planejadas, desde computadores, internet e servidor próprio para aplicações web, até salas para reuniões diversas e testes no software desenvolvido. 


\section{Primeira etapa: levantamento e documentação dos requisitos}

A primeira etapa da pesquisa foi iniciada no segundo semestre de 2018 e baseou-se no estudo de como era o funcionamento da CAE naquele momento. Diversas reuniões presenciais com entrevistas não estruturadas foram realizadas com os gestores e servidores deste setor, sendo feita a devida documentação de todos os assuntos tratados para eventuais consultas futuras. Outra atividade conduzida foi a análise de documentos e formulários internos do setor utilizados nas tarefas cotidianas, promovendo assim uma ampla visão de quais informações eram importantes para os gestores e para o sistema como um todo. Naquele momento a equipe da pesquisa identificou a necessidade que o software funcionasse como uma aplicação web, permitindo o acesso remoto dos usuários e sendo escalável em termos de infraestrutura de armazenamento e processamento.

A partir do conhecimento obtido na primeira etapa dos trabalhos, as atividades para levantamento dos requisitos para o software foram iniciadas. Para o refinamento e entendimento complementar dos requisitos foram conduzidas novas reuniões e entrevistas não estruturadas junto aos servidores da CAE. A versão final dos requisitos foi documentada no formato de História de Usuário. A Figura 1 apresenta a História de Usuário que ilustra as características do login no sistema.

Figura 1: História de Usuário do login do sistema

\begin{tabular}{|c|c|c|c|}
\hline \multirow{2}{*}{$\begin{array}{l}\text { Número: } 01 \\
\text { Data: } 10 / 08 / 2018\end{array}$} & \multicolumn{3}{|c|}{ Tipo de História: (x) Nova ( ) Melhoria } \\
\hline & Prioridade: 1 & Risco: Baixo & Estimativa: 12 horas \\
\hline \multicolumn{4}{|c|}{$\begin{array}{l}\text { Descrição: } \\
\text { Como usuário do sistema, eu desejaria fazer login utilizando meu CPF e minha senha, bem como ter a } \\
\text { possibilidade de recuperar meus dados de acesso a qualquer momento. }\end{array}$} \\
\hline \multicolumn{4}{|c|}{$\begin{array}{l}\text { Testes de Aceitação: } \\
\text { TA01-01: O CPF informado é inválido ou indica usuário bloqueado. } \\
\text { TA01-02: A senha utilizada está sendo criptografada. } \\
\text { TA01-03: O sistema limita as tentativas incorretas de acesso. } \\
\text { TA01-04: O sistema grava um histórico dos acessos do usuário. } \\
\text { TA01-05: A recuperação dos dados de acesso é feita apenas com a val }\end{array}$} \\
\hline
\end{tabular}

Fonte: Própria (2020)

Com o intuito de proporcionar uma visão gráfica das principais funcionalidades disponíveis no sistema para seus usuários, um Diagrama de Caso de Uso geral foi elaborado e apresentado aos envolvidos com o projeto para validação do escopo que viria a ser 
desenvolvido. Tal recurso pode ser observado na Figura 2.

Figura 2: Diagrama de Caso de Uso geral do sistema

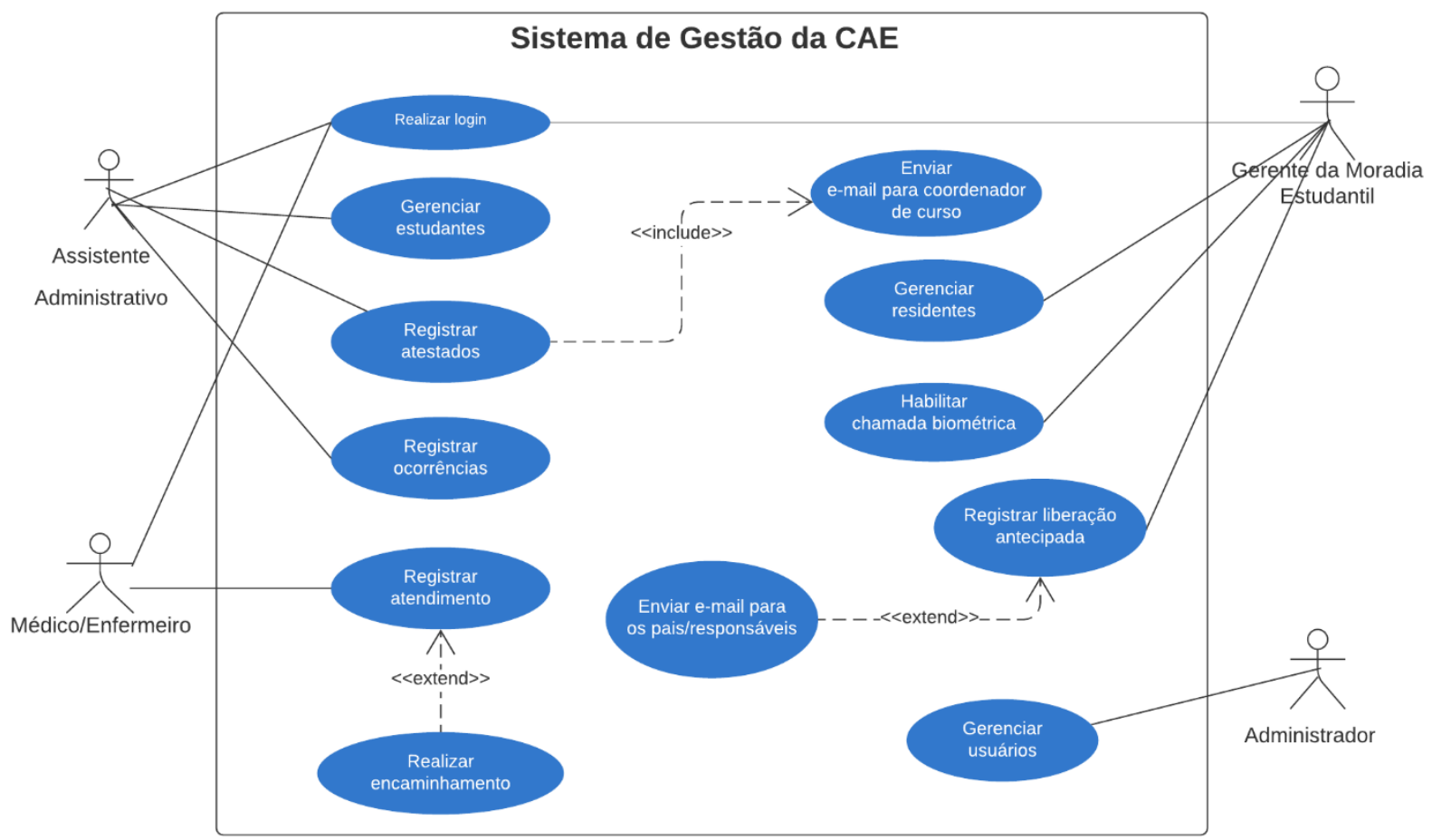

Fonte: Própria (2020)

A partir da definição inicial das funcionalidades do sistema e do entendimento dos requisitos para o seu desenvolvimento, foi elaborado o modelo dos dados na ferramenta MySQL Workbench versão 6.3, o qual proporcionou uma visão mais abrangente sobre a estrutura para armazenamento das informações gerenciadas pelo sistema. Considerando os conhecimentos prévios da equipe da pesquisa, simplicidade de configuração/manutenção e gratuidade para utilização, optou-se pela implementação do banco de dados no Sistema Gerenciador de Banco de Dados (SGBD) MySQL Community Server Edition versão 5.7. A Figura 3 apresenta o modelo de dados construído para o sistema da CAE. 
Figura 3: Modelo de dados do sistema

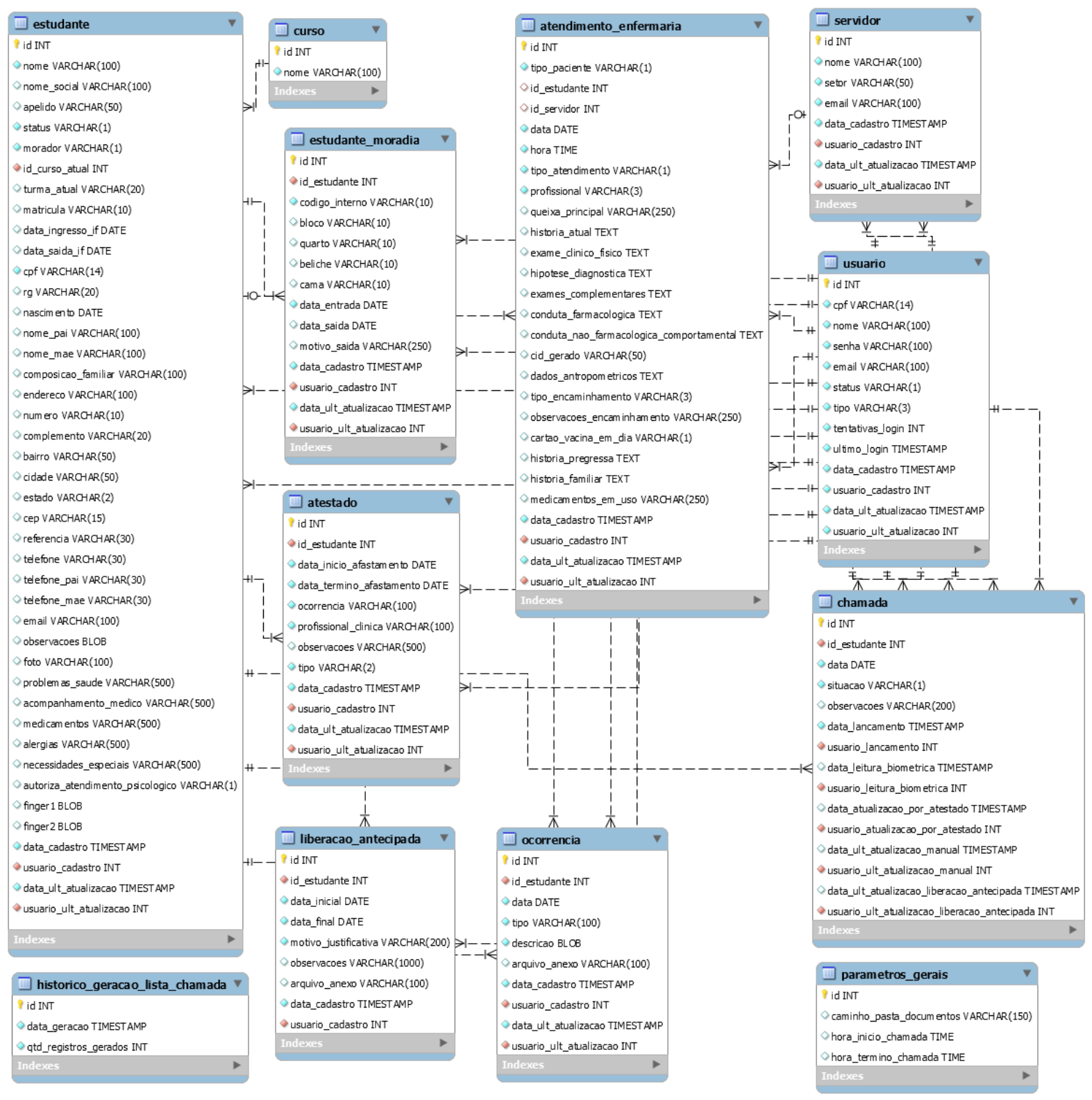

Fonte: Própria (2020)

Em relação às tecnologias para desenvolvimento do sistema, a definição das mesmas baseou-se nos conhecimentos prévios da equipe e no fato de serem de uso livre. A produção do front-end da aplicação web foi executada com o apoio das tecnologias HyperText Markup Language (HTML 5), Cascading Style Sheets (CSS 3), JavaScript, Bootstrap 4, jQuery 3 e Asynchronous Javascript and XML (AJAX), enquanto a produção do back-end foi baseada em PHP 7, framework CodeIgniter 3 e servidor Apache 2.5. 


\section{Segunda etapa: desenvolvimento da primeira versão do software}

Os recursos relacionados com o acesso ao sistema fizeram parte da versão inicial desenvolvida (Sprint 1), sendo o login a primeira funcionalidade implementada pela equipe. Os usuários podem realizar o acesso ao sistema informando seu CPF e uma senha previamente cadastrada pelo Administrador do ambiente. Para aumentar a segurança em relação ao acesso ao sistema, todas as senhas são armazenadas criptografadas no banco de dados e é feita uma limitação das tentativas de acesso não autorizadas para cada usuário. Sendo o acesso feito com sucesso, é criada uma sessão que permanece ativa durante 4 horas, ocorrendo a renovação automática no caso de interações do usuário com funcionalidades do sistema. Dentro do escopo de acesso ao sistema, foi desenvolvido também o recurso de gestão dos usuários, cujo objetivo principal é permitir ao Administrador gerenciar as informações de todas aquelas pessoas que utilizam o sistema.

Considerando a priorização das funcionalidades definidas no momento da criação do backlog do projeto, a segunda funcionalidade implementada foi o recurso de gestão dos estudantes que utilizam os serviços da CAE. Nesta rotina o usuário precisa cadastrar desde dados simples, como nome e números de documentos, até dados mais específicos que serão utilizados pelos gestores da CAE como, por exemplo, questões de saúde do estudante. O cadastro dos estudantes que residem na Moradia Estudantil do campus possui um número maior de campos para preenchimento, pois são informações que podem, eventualmente, ser utilizadas pelos servidores em momentos específicos, como na liberação dos alunos em finais de semanas ou no momento das chamadas diárias. Por fim, foi implementada uma rotina para inclusão da foto do estudante, de maneira a facilitar a identificação de cada indivíduo se assim for necessário (por exemplo, quando do lançamento de uma ocorrência disciplinar).

Ainda dentro do escopo do desenvolvimento da primeira versão do sistema, foi implementada a funcionalidade para gestão dos atestados médicos entregues pelos estudantes e validados pela CAE. Os usuários podem inserir dados específicos do atestado como a sua duração e o médico emissor e, caso seja necessário, anexá-lo para futuras consultas. Uma yez que se trata de dados sensíveis e particulares, apenas o Administrador pode ter acesso aos documentos que porventura tenham sido anexados. Neste momento é importante salientar que o sistema armazena um histórico completo de todas as inclusões, alterações, exclusões e acessos a registros, sendo factível, portanto, identificar o responsável por qualquer uma dessas ações para cada registro arquivado na base de dados. Outra funcionalidade desenvolvida nesta ocasião foi a de registro de ocorrências (disciplinares ou não) de estudantes, situação rotineira no cotidiano da CAE. As ocorrências podem ser classificadas em públicas ou particulares, 
sendo essas últimas acessíveis apenas pelo usuário que as cadastrou e pelo Administrador do sistema.

A última funcionalidade entregue na versão inicial do sistema foi o gerenciamento de atendimentos feitos pela Enfermaria do campus, local onde estudantes e também servidores são recebidos para prestação de primeiros socorros e consultas diversas. Ressalta-se que nesta versão inicial os dados demandados pelo Médico do campus não foram incluídos no cadastro, apenas aqueles relacionados ao atendimento prestado pelo Enfermeiro. A complementação da gestão dos atendimentos médicos foi inserida na segunda versão do sistema, quando as demandas do Médico em relação aos dados necessários para sua atuação foram melhor compreendidas e documentadas.

O próprio ambiente de desenvolvimento foi utilizado para a realização dos testes iniciais na primeira versão elaborada, sendo tais tarefas cumpridas pela equipe da pesquisa. Ao mesmo tempo, optou-se por disponibilizar uma cópia local do sistema para alguns servidores da CAE testarem as funcionalidades desenvolvidas. Foi realizado um treinamento prévio para todos os usuários que fizeram parte deste momento de testes iniciais. Pequenos ajustes foram solicitados pelos servidores da CAE, os quais foram prontamente realizados pela equipe da pesquisa a fim de que a primeira versão fosse considerada como pronta para uso em produção. Neste momento, o setor de Tecnologia da Informação do campus disponibilizou um ambiente próprio para hospedagem do sistema, cuja configuração foi concluída e permitiu que o sistema passasse a ser utilizado oficialmente pela CAE no início de 2019.

\section{Terceira etapa: desenvolvimento da segunda versão do software}

O desenvolvimento da segunda versão do sistema (Sprint 2) foi iniciada tão logo a primeira entrou em produção, focando a implementação de funcionalidades específicas para auxiliar o gerenciamento dos processos internos da Moradia Estudantil. Enquanto os usuários (servidores) faziam a alimentação dos dados de cadastros básicos no ambiente de produção, a funcionalidade denominada Mapa de Quartos foi desenvolvida. Nesta rotina o servidor da CAE pode visualizar a distribuição dos estudantes residentes na Moradia por unidade (de acordo com o sexo), quarto e beliche ocupados. Esta informação é importante para auxiliar o gestor da Moradia Estudantil na definição da mais adequada alocação dos estudantes dentre as vagas e locais disponíveis.

A Moradia Estudantil possuía alguns processos internos relacionados com o controle de presença dos residentes, até então dependentes da ação de seus servidores, cujos dados 
eram preenchidos em formulários de papel. O primeiro deles a ser projetado no sistema foi a liberação antecipada, rotina onde o servidor preenche os dados de determinado estudante, que ficará dispensado de se apresentar na Moradia durante um período específico e mediante devidas justificativas, como viagem em feriados prolongados para a cidade dos pais ou participação em eventos externos ao campus. Assim que a liberação de um estudante é cadastrada, o sistema armazena esta informação em um local específico para tratar a chamada do período liberado, uma vez que neste caso o estudante está resguardado e não pode constar como ausente.

O segundo processo interno da Moradia Estudantil implementado no sistema foi o controle de frequência dos estudantes residentes, o qual demandou o desenvolvimento de algumas funcionalidades com escopo bem delimitado. Inicialmente foi criado um serviço no SGBD MySQL para que, assim que um novo dia é iniciado no servidor, um registro de frequência é gerado para todos os residentes com a situação "Falta". A proposta é que os estudantes fiquem com falta até que comprovem a presença na Moradia, o que é feito durante um período de tempo parametrizado pelo gestor do local, ocorrendo normalmente durante o início da noite. Foi implementada também uma rotina para que os usuários Administradores possam consultar a geração de listas de chamadas, possibilitando analisar diariamente se os registros de frequência foram gerados corretamente pelo SGBD.

Ainda dentro do escopo do controle de frequência, a equipe da pesquisa implementou a funcionalidade de chamada dos residentes. Como a identificação dos estudantes deveria ser feita com base na leitura da impressão digital, inicialmente o cadastro de dados dos moradores foi alterado para permitir o armazenamento de duas impressões digitais para cada estudante. O gestor da CAE optou pela padronização de utilizar o dedo indicador de cada mão. Esta modificação permitiu que a rotina de chamada fosse construída tendo como foco a simplicidade. O estudante deve apenas informar seu CPF e, em seguida, posicionar no leitor biométrico a digital de um de seus dedos previamente cadastrados para que o sistema realize as devidas validações (se o estudante é residente da Moradia, se está suspenso por algum motivo, se já havia indicado a presença anteriormente) e altere a situação da chamada para "Presente". O leitor biométrico adquirido pelo campus e utilizado no sistema foi o Nitgen Fingkey Hamster III HFDU06S 9 .

Para que os servidores da CAE possam gerenciar os dados armazenados de chamadas realizadas, foi implementada uma rotina denominada "Espelho da Chamada", onde os 
registros podem ser alterados em situações específicas. Nesta página o usuário pode, por exemplo, alterar a situação da chamada (informando a devida justificativa para tal), gerar um relatório mensal da situação de frequência de cada estudante (ou de um grupo deles) e outro relatório com informações consolidadas sobre o controle de frequência dos residentes da Moradia Estudantil. Por fim, a rotina de gerenciamento de atestados foi alterada, de maneira que quando um estudante apresenta a justificativa para a ausência em determinado período o sistema automaticamente muda a situação dos registros de frequências para "Ausência justificada".

Encerrado o desenvolvimento das funcionalidades da segunda versão, a mesma foi validada em um ambiente de testes similar ao de produção. Enquanto os cadastros gerais foram testados por alguns membros da equipe da CAE, a rotina de controle de frequência foi avaliada durante dois meses envolvendo quatro quartos da Moradia Estudantil. O registro da frequência foi realizado, diariamente, na entrada do prédio principal da Moradia, sendo disponibilizados dois leitores, um para os estudantes do sexo masculino e outro para as estudantes do sexo feminino. Em seguida, a versão em produção foi atualizada com as novas funcionalidades e disponibilizada para todos os usuários do sistema.

\section{RESULTADOS E DISCUSSÃO}

Desde a implantação da primeira versão do sistema em produção, ocorrida no início de 2019, os servidores da CAE interromperam o uso de formulários em papel ou eletrônicos (por meio de documentos de texto ou planilhas eletrônicas) daquelas funcionalidades já implementadas e testadas. Optou-se pela utilização plena do sistema para que a rotina antiga de trabalho não impactasse na familiarização dos usuários com a nova ferramenta. Para que isto fosse possível, treinamentos foram realizados com os servidores e houve um acompanhamento frequente dos gestores da CAE desde o início do projeto.

Em relação aos aspectos técnicos do sistema produzido, a equipe de pesquisa preferiu desenvolver um projeto visual padronizado e simplificado, de maneira que os usuários não tivessem dificuldades para encontrar as funcionalidades disponíveis nem enfrentassem problemas na utilização das rotinas. Neste sentido, todas as interfaces gráficas do sistema apresentam o mesmo padrão de formato gráfico, considerando-se desde aspectos de cores e tipografia até os elementos inseridos nos formulários. Na Figura 4 é possível visualizar a página para manutenção dos dados dos estudantes cadastrados no sistema e constatar a simplicidade dos elementos gráficos selecionados. É válido ressaltar que são fictícios os dados 
apresentados; eles foram inseridos no processo de validação das funcionalidades desenvolvidas.

Figura 4: Página para manutenção dos dados dos estudantes

\begin{tabular}{|c|c|c|c|c|c|c|}
\hline \multicolumn{5}{|c|}{ Estudantes } & \multicolumn{2}{|c|}{\begin{tabular}{l|l} 
Pesquisar & Novo Estudante
\end{tabular}} \\
\hline ID & Nome & CPF & Curso atual & Última atualização & & Açōes \\
\hline 4 & Abel Carvalho Fernandes & $160.118 .345-05$ & $\begin{array}{l}\text { Bacharelado em Engenharia da } \\
\text { Computação }\end{array}$ & 29/10/2019 23:33:07 & 16 & $\because 0$ 口回 \\
\hline 2 & Clara Guimarães Melo & 222.222.222-22 & Bacharelado em Administração & 12/09/2018 19:54:29 & 16 & $\approx 00$ 回 \\
\hline 5 & Fernanda Cristina Carvalho Guimarães & 444.555.666-77 & Bacharelado em Medicina Veterinária & 29/10/2019 23:38:25 & $\angle 6$ & 00 国 \\
\hline 7 & Josefrido Cardoso & $122.122 .122-12$ & Bacharelado em Engenharia de Alimentos & 29/10/2018 10:48:57 & $\angle 6$ & $\because 00$ 四 \\
\hline 1 & Lucca Guimarães Melo & 123.456.789-10 & $\begin{array}{l}\text { Técnico em Manutençăo Automotiva } \\
\text { Subsequente }\end{array}$ & 05/11/2019 00:39:00 & -6 & $\because 0$ 四 \\
\hline
\end{tabular}

Fonte: Própria (2020)

Para melhorar a experiência dos usuários, foi implementada no sistema a proposta de utilização de janelas modais para manipulação dos dados. Quando uma página é carregada, a listagem de registros relacionados é exibida; caso o usuário acione opções como alteração ou inclusão de registros, a janela com o formulário de dados é exibida de maneira sobreposta à listagem, ficando esta bloqueada até que a janela modal seja fechada. A Figura 5 ilustra esse comportamento do sistema ao apresentar a janela modal para alteração dos dados de um estudante fictício.

Figura 5: Alteração dos dados de um estudante por meio de uma janela modal

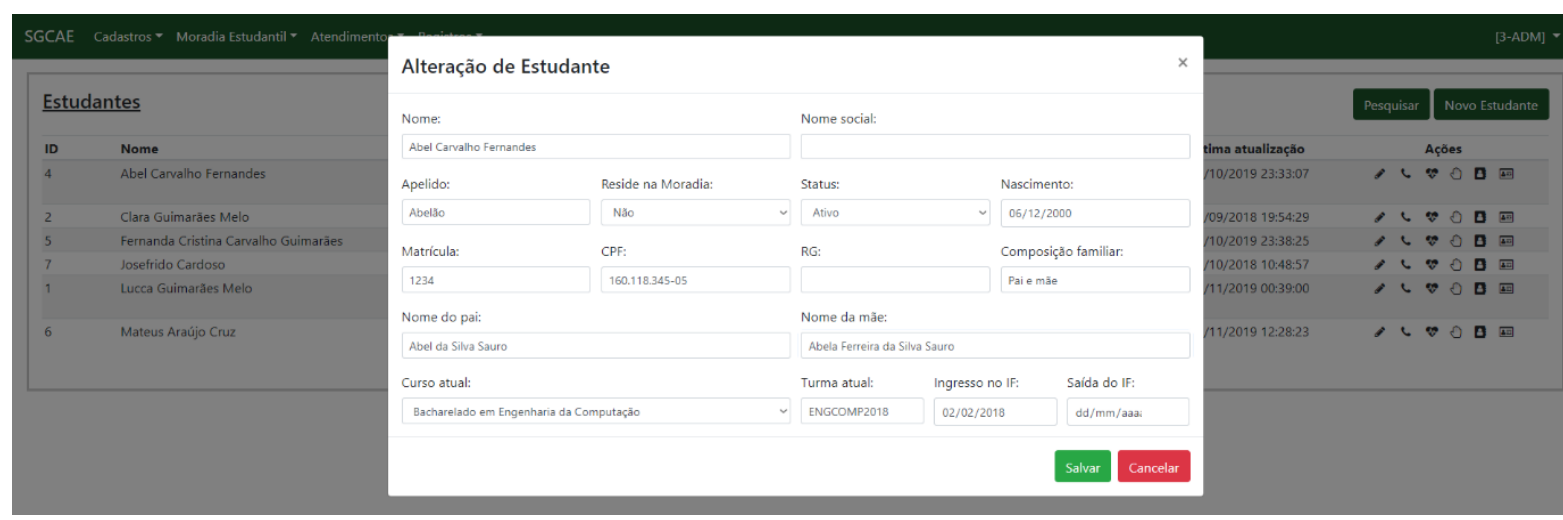

Fonte: Própria (2020)

Para efeitos de padronização das páginas e janelas do sistema, as listagens de dados incluem botões de ação vinculados a cada registro apresentado, bem como um botão específico para inserção de novos dados e outro para que o usuário possa refinar sua pesquisa com o auxílio de filtros em campos específicos. Esta opção de filtragem dos dados foi enfatizada pelos gestores da CAE quando das reuniões de levantamento de requisitos para o sistema como tendo fundamental importância para os usuários, principalmente se for levado 
em consideração o volume de dados que esperava-se, naquele momento, que seria gerado a partir da constante utilização da ferramenta. Ressalta-se que os campos disponíveis para filtragem de registros variam entre as páginas do sistema. A Figura 6 apresenta a janela modal com as opções de pesquisa relacionadas com os dados dos atestados.

Figura 6: Opções de pesquisa para filtragem de dados

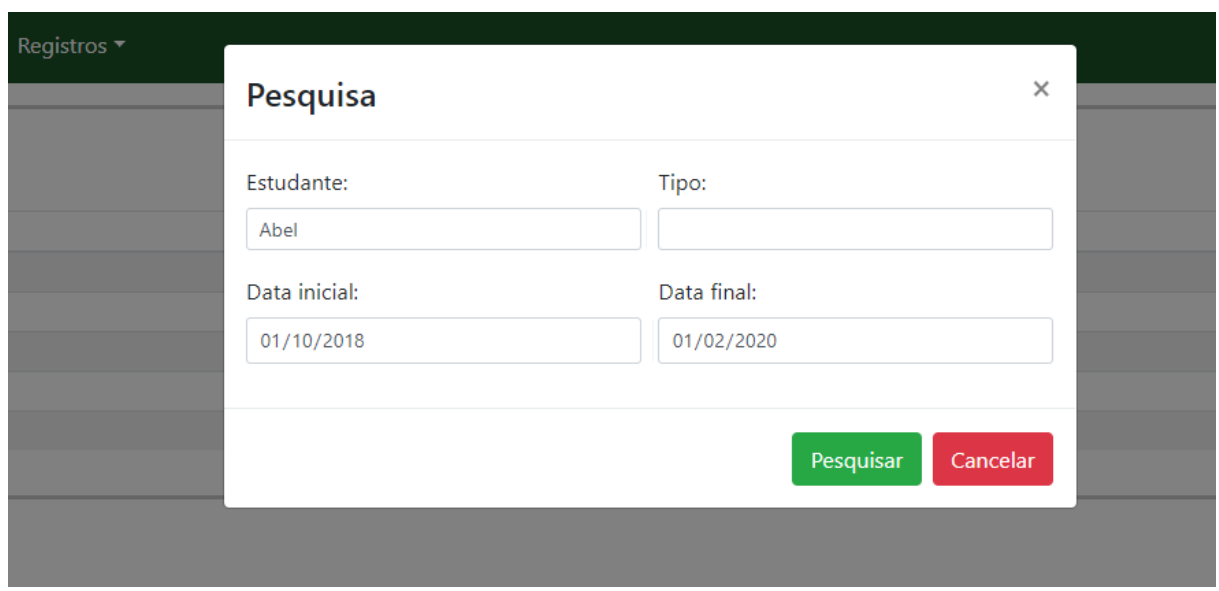

Fonte: Os Autores (2020)

A funcionalidade do Mapa de Quartos possui uma interface mais específica, pois seus dados necessitam ser agrupados em dois níveis: blocos e quartos. Assim como se pode observar a partir da análise da Figura 7, o gestor tem uma visão mais abrangente da ocupação dos espaços da Moradia Estudantil por esta página. Até a utilização do sistema, a divisão dos estudantes por quartos era uma tarefa extremamente trabalhosa, de acordo com os gestores da CAE, pois as informações de blocos e quartos ficavam espalhadas em diferentes arquivos, alguns no formato de documento de texto e outros como planilhas eletrônicas.

Figura 7: Funcionalidade de Mapa de Quartos

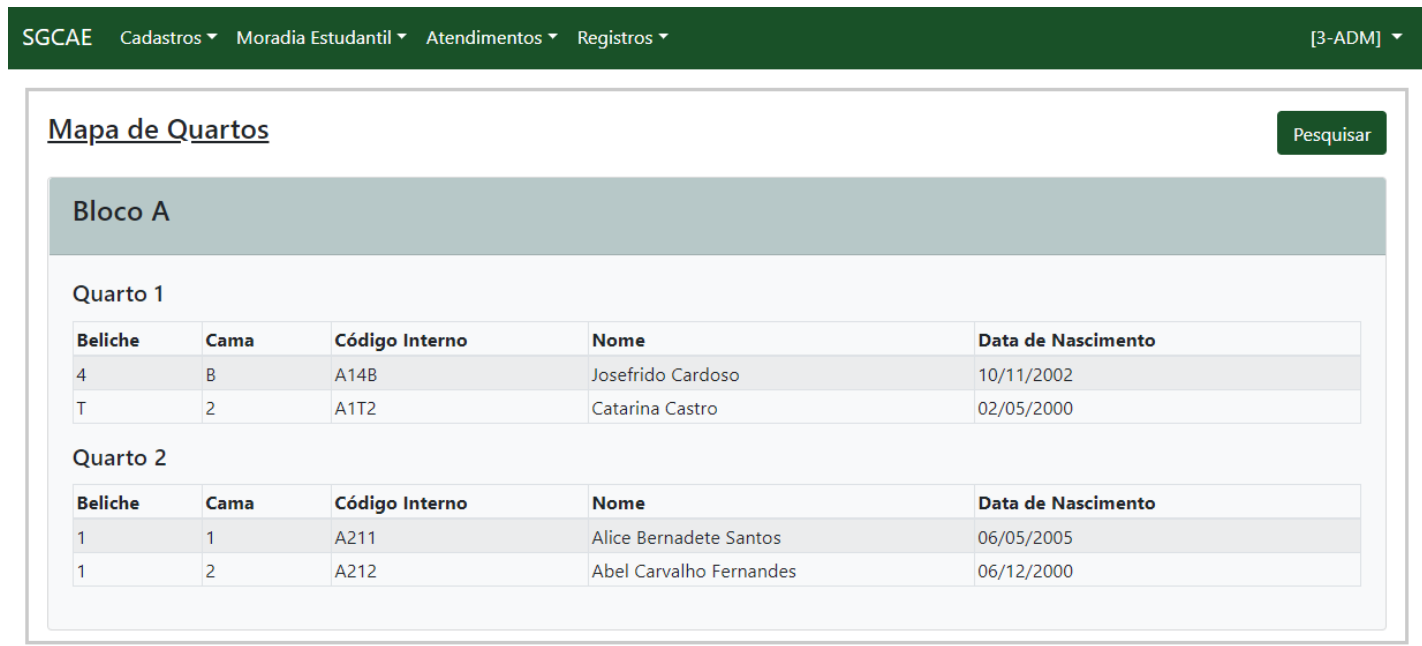

Fonte: Própria (2020)

Conforme exposto anteriormente, o processo de registro de frequência foi idealizado 
para ser de fácil manuseio, em especial por parte dos estudantes. A Figura 8 apresenta a página para realização das chamadas diárias; nela é possível visualizar o campo para preenchimento pelo estudante de seu CPF e um botão para iniciar o processo de leitura da impressão digital. O tempo gasto por um estudante desde o início da rotina até a sua finalização tem sido, em média, de 10 (dez) segundos. O período da chamada pode ser parametrizado pelo Administrador do sistema, fazendo com que até o momento não tenham sido geradas filas para registro da frequência por parte dos estudantes.

Figura 8: Página para registro de frequência com auxílio de leitor de impressão digital

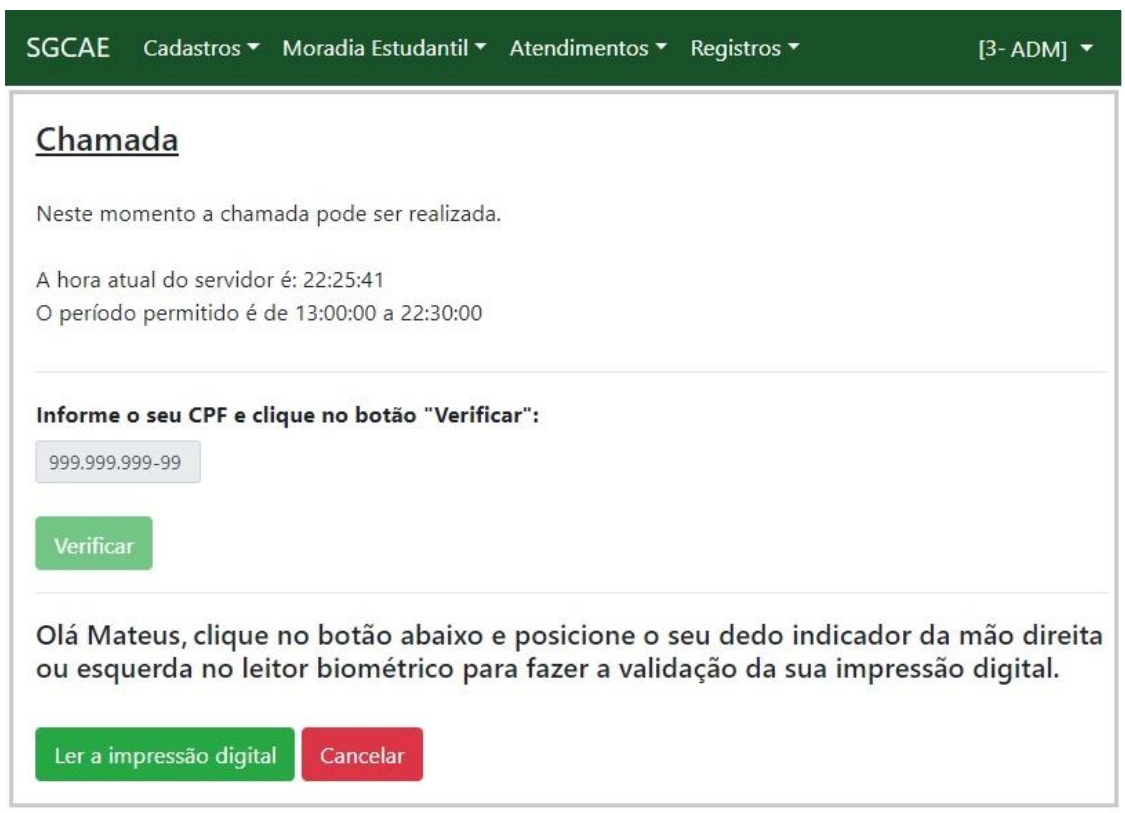

Fonte: Própria (2020)

Uma das grandes possibilidades do sistema está relacionada à geração e obtenção de informações sobre os registros inseridos no banco de dados, o que até então não era possível ou, no melhor dos casos era muito complexo, em função da utilização de documentos de texto e planilhas eletrônicas dispersas entre os usuários do setor. Durante o primeiro ano de utilização do sistema (2019), foram registrados eletronicamente 1.125 atestados médicos, 797 ocorrências, 551 atendimentos no setor de enfermaria e 985 liberações antecipadas de estudantes que residem na Moradia Estudantil. Tais números não podem ser comparados com dados de anos anteriores em função da baixa confiabilidade dos indicadores disponíveis na CAE, até então. Em relação à Moradia, o processo de controle de frequência (e suas rotinas auxiliares) já passou a fazer parte do cotidiano de estudantes e servidores vinculados à CAE. Houve otimização do trabalho de dois servidores que atuam na Moradia, pois antes da implantação do sistema eles percorriam cada um dos quartos para fazer a chamada 
manualmente em papel e, assim que finalizada, os dados eram preenchidos em uma planilha eletrônica. Neste sentido, o sistema desenvolvido trouxe importantes ganhos de produtividade, haja vista que o processo de chamada foi automatizado e a emissão de relatórios gerenciais é feita a qualquer momento, não necessitando de nenhum tipo de preenchimento manual por parte dos servidores.

Finalmente, um dos grandes propósitos da pesquisa foi alcançado, pois a partir da implantação e utilização frequente e correta do sistema pelos servidores da CAE, tornou-se possível a emissão de um relatório consolidando todas as informações sobre determinado estudante. Em suma, esta rotina exibe todo o histórico de um estudante selecionado, apresentando suas informações de cadastro, atestados entregues, ocorrências nas quais teve envolvimento, atendimentos no setor de enfermaria e controle da frequência na Moradia Estudantil (caso seja residente). A expectativa é que tal documento passe a ser utilizado (com o devido sigilo) também pelos gestores dos cursos e pela Diretoria de Ensino no intuito de conhecer melhor o perfil dos estudantes do campus, identificando suas demandas, dificuldades e características.

\section{CONCLUSÕES}

Os resultados obtidos a partir da execução desta pesquisa evidenciam que a gestão pode ser beneficiada pela utilização de recursos tecnológicos, tais como softwares, desde que os mesmos apresentem a devida adequação e aderência ao ambiente em questão e que, tanto gestores quanto outros tipos de usuários estejam dispostos a apoiar uma forma de trabalho mais moderna e dinâmica.

Percebeu-se, entre outras referências positivas, que os problemas de gerenciamento das informações da Assistência Estudantil do IFMG - Campus Bambuí são agora melhor tratados com o apoio do sistema construído, pois todas as funcionalidades desenvolvidas estavam estritamente de acordo com as demandas dos servidores que lá atuam. Ademais, foi possível notar que os processos de trabalho foram facilitados, mesmo ao considerar-se naturais dificuldades advindas do uso de uma nova ferramenta e de novos métodos de trabalho. O compartilhamento de informações passou a ser possível, independentemente do servidor que as detém, pois mesmo com os perfis definidos pelo sistema os dados básicos podem ser acessados por aquelas pessoas que realmente necessitam deles para a tomada de alguma decisão.

Outros benefícios obtidos pela utilização do sistema foram a redução na quantidade de 
papel utilizado no cotidiano do setor e o acesso mais rápido às informações, seja de um estudante específico ou daquelas consolidadas de determinados indicadores. A integração dos dados também foi facilitada pelo sistema, pois ao utilizar uma base de dados centralizada e padronizada, a geração de informações fica mais simples de ser processada, neste caso em formato de relatórios gerenciais cujo modelo foi definido previamente pelos servidores da CAE. A rotina de backup desta base de dados em nuvem permite também que, caso ocorra algum novo incidente com a infraestrutura de TI do campus, os dados não se percam.

Uma dificuldade enfrentada durante a execução das atividades da pesquisa que merece menção refere-se às repetidas mudanças do coordenador da Assistência Estudantil do IFMG Campus Bambuí, evento ocorrido por três vezes até o presente momento. Tal fato criou situações que atrasaram o desenvolvimento de algumas funcionalidades do sistema, pois até que os novos gestores tomassem conhecimento do mesmo e indicassem sugestões de ajustes, as tarefas de implementação ficaram pendentes para evitar possíveis retrabalhos.

Quando um software é disponibilizado em ambiente de produção para seus usuários entende-se que ele, na verdade, está apenas começando a ter sua vida dentro da organização. É comum que correções, ajustes e melhorias sejam demandados pelos usuários para que, efetivamente, o sistema possa contribuir de acordo com o que era esperado. Neste sentido, esta pesquisa pode ser melhorada a partir de uma integração com o sistema acadêmico utilizado pelo campus para gestão das informações dos estudantes. Tal ação não foi possível pelo fato de o sistema atualmente utilizado ser de propriedade particular de uma empresa e não disponibilizar uma interface para comunicação externa direta com outras aplicações. Outra melhoria sugerida é a integração com o sistema utilizado pelo Restaurante Universitário, fazendo com que novas informações sejam agregadas ao histórico de cada estudante cadastrado no sistema da CAE. Por fim, é necessário que outras áreas de atuação da CAE, como Psicologia e Nutrição, tenham seus processos internos mapeados e implementados no sistema para que os servidores que nelas atuam também possam usufruir da ferramenta tecnológica ao planejar e executar suas ações.

\section{REFERÊNCIAS}

ARAÚJO, B. D. L.; PINHEIRO JÚNIOR, F. M. L.; ABREU, F. P. Gerenciamento de aquisições de soluções de tecnologia da informação em uma universidade pública do Ceará. Revista Gestão em Análise, v. 4, n. 1, p. 43-53, 2015.

ASSIS, W. C. Governança de TI na administração Pública Federal: aprimorando a 
governança de TI no setor público brasileiro. 2016. Disponível em: http://repositorio.uniceub.br/jspui/handle/235/8064. Acesso em: 17 jul. 2020.

BATISTA, E. O. Sistemas de Informação. São Paulo: Saraiva, 2017.

BROGNOLI, T. S.; FERENHOF, H. A. Transformação Digital no governo brasileiro: desafios, ações e perspectivas. Navus - Revista de Gestão e Tecnologia, [S.1.], v. 10, p. 01-11, jan/dez. 2020. ISSN 2237-4558. Disponível em: <http://navus.sc.senac.br/index.php/navus/article/view/989/pdf>. Acesso em: 24 ago. 2020.

CAE. Coordenadoria de Assistência Estudantil (CAE) do IFMG - Campus Bambuí. Disponível em: <http://bambui.ifmg.edu.br/portal/cae>. Acesso em: 18 jul. 2020.

CGTI. Sistemas de Informação da Coordenadoria de Gestão de Tecnologia da Informação do IFMG - Campus Bambuí. Disponível em: http://www.bambui.ifmg.edu.br/portal/cgti/sistemas-de-informacao. Acesso em: 18 jul. 2020.

DIAS, T. F.; SANO, H.; MEDEIROS, M. F. M. Inovação e tecnologias da comunicação e informação na administração pública. Brasília: ENAP, 2019.

FREITAS, A. L. S.; CREMASCO JÚNIOR, D.; SOUZA, M. P. Transição da gestão de tecnologia da informação para a governança eletrônica na Universidade Federal de Rondônia. 2015. Disponível em: https://repositorio.ufsc.br/handle/123456789/136120. Acesso em: 15 ago. 2020.

FREITAS, E. C. de; PRODANOV, C. C. Metodologia do Trabalho Científico: Métodos e Técnicas da Pesquisa e do Trabalho Acadêmico. 2. ed. Novo Hamburgo: Feevale, 2013.

GIL, A. C. Métodos e Técnicas de Pesquisa Social. 7. ed. São Paulo: Atlas, 2019.

GOMES FILHO, A. C. Gestão de Tecnologia da Informação: Abordagem para o Setor Público. 2018. Disponível em: http://repositorio.unicentro.br:8080/jspui/bitstream/123456789/1314/1/GOMES_Gestao_de\% 20TI_abordagem_para_setor_publico.pdf. Acesso em: 23 ago. 2020.

LAUDON, K.; LAUDON, J. Sistemas de Informações Gerenciais. São Paulo: Pearson, 2015.

MARCHIORI, D. M.; MAINARDES, E. W. A Relação Entre os Fatores Criadores do Technostress e a Qualidade Percebida de Serviços de Tecnologia da Informação. ENCONTRO SEMINÁRIOS EM ADMINISTRAÇÃO (SEMEAD), v. 18, 2015.

MATTOS, A. C. M. Sistemas de Informação: uma visão executiva. 2. ed. São Paulo: Saraiva, 2017.

RABELO, C. L. A. et al. A participação da sociedade no governo eletrônico sob a perspectiva da democracia digital. Revista Argumentum-Argumentum Journal of Law, v. 13, p. 225-255, $2019 . \quad$ Disponível http://ojs.unimar.br/index.php/revistaargumentum/article/view/1093/687. Acesso em: 15 ago. 2020. 
ROZA, R. H. Revolução informacional e os avanços tecnológicos da informática e das telecomunicações. Ciência da Informação em Revista, v. 4, n. 3, p. 3-11, 2017.

SILVA, R. T. et al. Gestão por Processos em Tecnologia da Informação: um estudo em uma empresa de médio porte. Revista de Administração do UNIFATEA, v. 12, n. 12, 2016.

SILVEIRA, D. T.; CÓRDOVA, F. P. A pesquisa científica. Porto Alegre: UFRGS, 2009.

SORDI, J. O.; MEIRELES, M. Administração de Sistemas de Informação. 2. ed. São Paulo: Saraiva, 2018.

SZIMANSKI, F. et al. Reestruturando a Área de Tecnologia da Informação: um relato de experiência na administração pública. In: Anais do XI Simpósio Brasileiro de Sistemas de Informação. SBC, 2015. p. 475-482.

VILELA, B. D. et al. Coordenação em cadeias de suprimentos: o papel da tecnologia da informação e da gestão orientada por processos. Exacta, v. 14, n. 4, p. 645-660, 2016.

WAZLAWICK, R. S. Metodologia de pesquisa para ciência da computação. 2 . ed. Rio de Janeiro: Elsevier, 2014.

ZORZAL, L. Transparência das informações das universidades federais: estudo dos relatórios de gestão à luz dos princípios de boa governança na Administração Pública Federal. 2015. Disponível em: http://repositorio.unb.br/handle/10482/19202. Acesso em: 15 abr. 2020. 